Introduction Febrile urinary tract infections (FUTIs) are a common reason of consultation and hospitalization in pediatric clinical practice generating important health care costs. Strains of multidrug-resistant bacteria responsible for FUTIs are currently emerging, which can, in many cases, lead to therapeutic dead-ends. However, the changing epidemiological and bacteriological profiles of FUTIs in children over the past years haven't been studied in Tunisia.

The main purpose of this study was to analyze the evolution of epidemiological and bacteriological profiles of FUTIs in children.

Methods It was a descriptive, analytical and retrospective study over two periods (2000-2005 and 2010-2015), conducted in the department of pediatrics C at the children's hospital Bechir Hamza of Tunis. We included all children who were hospitalized for confirmed FUTIs.

Results This study enrolled 254 patients divided into 2 groups: group 1 which included 105 patients from the first study period and group 2 which included 149 patients of the second period of study. The average age was significantly lower in group $2 \quad(51.2 \pm 39.7$ months versus $32.2 \pm 38.4$ months; $\mathrm{p}<0.001$ ) with a female predominance in both groups. A history of malformativeuropathies and UTIs was more common in the first study group.

Clinical features were similar in both groups. Escherichia coli (E. coli) was the most frequently isolated germ. The antibiograms showed an increase in the resistance rates of E. coli to ampicillin, third generation cephalosporins and gentamicin during the second period of study as compared to the first period. Imipenem and amikacin kept a zero resistance rate between the two periods of the study.

Conclusion Antibiotic resistance rates in upper UTIs have increased significantly over the past years. Preventing those risks requires a more rational prescription of antibiotics.

\section{A SYSTEMATIC REVIEW OF TRANSITIONAL CARE MODELS IN PAEDIATRIC RENAL TRANSPLANT RECIPIENTS}

'Dermot Wildes*, ${ }^{1} \mathrm{CS}$ Costigan, ${ }^{1} \mathrm{~N}$ Dolan, ${ }^{1,2} \mathrm{M}$ Riordan, ${ }^{1} \mathrm{C}$ Sweeney, ${ }^{1} \mathrm{M}$ Stack ${ }^{1} \mathrm{M}$ Waldron, ' $\mathrm{I}$ Flynn, ${ }^{1} \mathrm{M}$ Kinlough, ${ }^{1,2,3} \mathrm{~A}$ Awan. ${ }^{1}$ The Department for Paediatric Nephrology and Transplantation, Children's Health Ireland at Temple St., Temple Street, Dublin 1, Ireland; ' ${ }^{2}$ Department of Paediatrics, Royal College of Surgeons in Ireland, $123 \mathrm{St}$. Stephen's Green, Dublin 2, Ireland; ${ }^{3}$ Department of Paediatrics, UCD School of Medicine, University College Dublin, Belfield, Dublin 4, Ireland

10.1136/archdischild-2021-europaediatrics.373

Adolescence is a time of significant change and challenge for clinicians, parents, and patients. The Paediatrician must ensure patients have the necessary skills and knowledge required to function as an individual, with autonomy and self-care. It is well established that adolescent renal transplant recipients have a high incidence of acute allograft rejection and loss. ${ }^{1}$ The transfer from paediatric to adult care carries an increased risk of graft-related complications attributable to a multitude of reasons, particularly non-adherence to immunosuppressant medicines and poor attendance at scheduled appointments. ${ }^{2-6}$ We aim to present a summary of published, peer-reviewed transitional care models for adolescent renal transplant recipients with a description of their respective approaches.

A systematic review was performed, in a methodology outlined by the PRISMA guidelines. ${ }^{7}$ MEDLINE OVID \&
EMBASE databases were searched for studies that outlined valid, replicable models pertaining to transitional care of paediatric renal transplant recipients between 1946 and Q1 2021. No language restrictions were applied and the reference lists of selected articles were also perused for further eligible studies. Two investigators assessed all studies for eligibility and independently performed data extraction, any discrepancies were settled by consensus.

A total of 1,114 abstracts were identified, which was reduced to 1,020, upon removal of duplicates yielded by the respective searches. We also consulted experts in the field for further eligible articles. A total of 49 articles were deemed appropriate for full-text review and critical appraisal. Eight articles were included in qualitative synthesis. Data were extracted from all included models in an endeavour to compare the approach taken in each respective case as follows: Country; clinical setting; transition facilitators; age at first transition clinic; age at transition.

Despite the well-established need for good transitional care in paediatric solid-organ transplant recipients, models tailored specifically for renal transplant recipients are few in number. Amongst those present, there is a notable degree of heterogeneity in approach. Further research and validation studies of these models are required, to ascertain the most efficacious method of providing effective transitional care to these patients.

\section{REFERENCES}

1. Dobbels F, Ruppar T, De Geest S, Decorte A, Van Damme-Lombaerts R, Fine RN Adherence to the immunosuppressive regimen in pediatric kidney transplant recipients: A systematic review. Pediatr Transplant 2010;14:603-613.

2. Keith DS, Cantarovich M, Paraskevas S, et al. Recipient age and risk of chronic allograft nephropathy in primary deceased donor kidney transplant. Transp/ Int 2006;19:649-656.

3. Dew MA, Dabbs AD, Myaskovsky $L$, et al. Meta-analysis of medical regimen adherence outcomes in pediatric solid organ transplantation. Transplantation 2009;88:736-746.

4. Watson AR. Non-compliance and transfer from pediatric to adult transplant unit Pediatr Nephrol 2000;14:469- 472.

5. Van Arendonk KJ, Boyarsky BJ, Orandi BJ, et al. National trends over 25 years in pediatric kidney transplant outcomes. Pediatrics 2014;133(4):594- 601.

6. Crowley R, Wolfe I, Lock K, McKee M. Improving the transition between paediatric and adult healthcare: A systematic review. Arch Dis Child 2011;96(6): 548553.

7. Moher D, Liberati A, Tetzlaff J, Altman DG, The PRISMA Group. Preferred reporting items for systematic reviews and meta-analyses: the PRISMA statement. PLoS Med 2009;6(7):e1000097. doi:10.1371/journal.pmed1000097

\section{PLASMA EXCHANGE IN PAEDIATRIC NEPHROLOGY - THE IRISH EXPERIENCE}

${ }^{1}$ Dermot Wildes*, ${ }^{1} \mathrm{C}$ Devlin, ${ }^{1} \mathrm{CS}$ Costigan, ${ }^{1} \mathrm{~J} \mathrm{Cox},{ }^{1} \mathrm{C}$ Hensey, ${ }^{1} \mathrm{M}$ Waldron, ${ }^{1} \mathrm{~N}$ Dolan, ${ }^{1} \mathrm{M}$ Riordan, ${ }^{1} \mathrm{C}$ Sweeney, ${ }^{1} \mathrm{M}$ Stack, ${ }^{1} \mathrm{~T}$ Raftery, ${ }^{2} \mathrm{M}$ Cotter, ${ }^{1} \mathrm{~A}$ Awan. ${ }^{1}$ The Department for Paediatric Nephrology and Transplantation, Children's Health Ireland, Temple St., Dublin 1, Ireland; 'The Department of Haematology, Children's Health Ireland at Temple St., Temple Street, Dublin 1, Ireland

\subsection{6/archdischild-2021-europaediatrics.374}

Plasma exchange (PLEX) has proven an effective modality in the management of many paediatric renal conditions. Despite its widespread acceptance, and advancements in the practice of apheresis, there remains a paucity of data pertaining to the paediatric patient population. The use of PLEX in paediatric patient cohorts is technically more challenging than in their adult counterparts, due to numerous factors which include the patient's size, extracorporeal circulatory volume, ability to 
tolerate therapy and the difficulties regarding care of vascularaccess ports in a younger cohort. ${ }^{1}$ Given the lack of data surrounding PLEX in Paediatrics, protocols are developed based on extrapolations from best-practice in adult populations, an area where work must be carried out to improve patient safety and outcome. We present a large cohort of paediatric patients undergoing therapeutic plasma exchange therapy for solely renal indications, across a period of 17 years.

A retrospective chart review was conducted for all patients (under 16 years) undergoing PLEX therapy for a renal indication, as specified by the ASFA Guidelines, between January 2002 \&amp June 2019. ${ }^{2}$ The following data were extracted, for each individual case: Age; gender; indication; complications; pre-medications; therapeutic outcome. Patients were stratified into groups as follows: STEC HUS; aHUS; Nephritis (C3GN, PIGN, anti-GBM, ANCA Vasculitis); IgA Nephropathy/HSP; Post-Transplant (recurrent FSGS, acute humeral rejection). This review was performed with permission from the CHI at Temple Street Research \& Ethics Committee.

A total of $\mathrm{n}=58$ patients were identified, 39.7\% were male $(n=23)$ and $60.3 \%$ were female $(n=35) .1137$ exchanges were performed. The median age of patients undergoing PLEX was 35.5 months. The most common indication was STEC HUS $(n=29)$. Fluid substitution was performed using 5\% AlbuminSaline or Plasma. Complications occurred in $n=38$ patients, with most experiencing minor complications. Asymptomatic hypocalcaemia was the most common complication experienced $(n=25)$. There were no deaths as a result of PLEX therapy.

We present our experience of plasma exchange (PLEX) therapy, spanning 1,137 exchanges across 17 years, proved a well-tolerated, highly efficacious therapy for a variety of renal pathologies, as listed above. Most complications experienced were minor in nature, and with therapy conducted in specialised centres, with appropriately paediatric-trained staff, there are very low levels of adverse events - most of which can be anticipated.

\section{REFERENCES}

1. Goldstein SL. Therapeutic apheresis in children: special considerations. Semin Dial 2012 Mar-Apr;25(2):165-70. doi:10.1111/j.1525-139X.2011.01028.x. Epub 2012 Jan 25. PMID: 22277133

2. Connelly-Smith L, Dunbar NM. The 2019 guidelines from the American Society for Apheresis: what's new?. Curr Opin Hematol 2019;26(6):461-465. doi:10.1097/ MOH.0000000000000534

\section{NEUROGENIC BLADDER DYSFUNCTION - EXPERIENCES OF THE DEPARTMENT OF PEDIATRICS IN UNIVERSITY HOSPITAL CENTRE SPLIT}

Prgomet Sandra*, Saraga Marijan, Arapović Adela, Todorić Jakov, Meštrović Marija, Tomasović Maja, Marušić Eugenija, Kuzmanić Šamija Radenka. University hospital Split

10.1136/archdischild-2021-europaediatrics.375

Neurogenic bladder is a bladder dysfunction caused by impaired innervation of the lower urinary tract. The most common causes of neurogenic bladder in children are congenital anomalies of the spinal cord. Acquired causes of neurogenic bladder in children can be: cerebral palsy, transverse myelitis, spinal cord tumors, trauma, progressive neurodegenerative diseases, multiple sclerosis, Guillain-Barre syndrome and iatrogenic damage to the pelvic plexus.
Urodynamic testing is the gold standard in the diagnosis and monitoring of children with neurogenic bladder.

The most common form of treatment is clean intermittent catheterization. In terms of drugs, anticholinergics are most commonly used. The main goals of treatment are to preserve renal function and achieve continence.

Children with neurogenic bladder are monitored in the Laboratory for Urodynamics and in the Voiding Disorders Clinic, Department of Pediatrics in University Hospital Centre Split. We retrospectively analyzed data from the medical records of children with neurogenic bladder in the period from Year 2015 to 2019.

Over a period of five years, neurogenic bladder was diagnosed in total of 20 girls and 16 boys. The mean age of diagnosis of neurogenic bladder was 8.3 years. The mean age of children with congenital anomalies of the spine and spinal cord was 4.9 years, while the mean age of children with acquired patterns of neurogenic bladder dysfunction was 11.0 years. Urodynamic examination was done in all children. The diagnosis of neurogenic overactive detrusor and detrusor sphincter dyssynergia was made in a total of 13 children with congenital anomalies and in 9 children with acquired anomalies. Thus, $61 \%$ of children had the most severe form of bladder dysfunction A total of fifteen children were treated with clean intermittent catheterization.

The anticholinergic was administered to ten children with neurogenic overactive detrusor and congenital anomalies and to eight children with acquired neurogenic bladder causes.

In most children with neurogenic bladder, early urodynamic diagnosis and early initiation of treatment may preserve renal function.

Further monitoring of our patients is needed.

\section{THE VALUE OF CONTRAST-ENHANCED VOIDING UROSONOGRAPHY (CEVUS) IN THE DIAGNOSIS OF INTRARENAL REFLUX (IRR) IN CHILDREN WITH LOW- GRADE VESICOURETERAL REFLUX (VUR) - A CASE REPORT}

Iva Palčić* Andrea Cvitković Roić, Goran Roić. Poliklinika za dječje bolesti Helena

\subsection{6/archdischild-2021-europaediatrics.376}

Objective Many studies have shown that intrarenal reflux (IRR) is an important risk factor for renal scarring and reflux nephropathy in children with vesicoureteral reflux (VUR). The incidence of IRR diagnosed by fluoroscopic voiding cystourethrography (VCUG) ranges below $1 \%$ to a maximum of $10 \%$ and is detected only in children with higher grades of VUR.

In our institution we have been using ultrasound methods for the diagnosis of VUR since 2006. Contrast-enhanced voiding urosonography (ceVUS) combined with harmonic imaging and second-generation ultrasound contrast media, which we introduced in 2013, has high diagnostic accuracy compared to VCUG in the detection of VUR. This method enabled IRR detection in almost $12 \%$ of our patients with VUR.

The diagnostic criterion for IRR using ceVUS is the appearance of contrast microbubbles outside the contours of the duct system or renal calyx and the entry of contrast into the renal parenchyma. By March 2021 we have had ten children with VUR gr II and IRR which demonstrates the possibility of ceVUS to detect IRR in children with low-grade VUR as well. We report one of the children with low-grade reflux and IRR. 